\title{
MAPPING AND MONITORING OF URBAN SPRAWL TO PROMOTE SUSTAINABLE URBANIZATION USING GEOSPATIAL TECHNIQUES
}

\author{
KHAN, M. R. ${ }^{1}-$ AMIN, M..$^{2 *}$ AHMAD, Z. ${ }^{2}-$ SAGIN, J. ${ }^{3}$

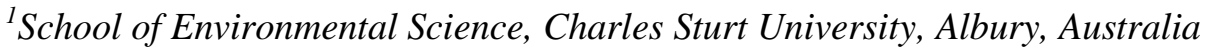 \\ ${ }^{2}$ Institute of Geo-Information \& Earth Observation, PMAS Arid Agriculture University, \\ Rawalpindi, Pakistan
}

${ }^{3}$ The Environment \& Resource Efficiency Cluster (EREC), Nazarbayev University, Nur-Sultan, Kazakhstan

*Corresponding author

e-mail:m.amin@uaar.edu.pk

(Received $6^{\text {th }}$ May 2021; accepted $29^{\text {th }}$ Jul 2021)

\begin{abstract}
Urbanization is a global phenomenon, but in undeveloped countries like Pakistan, urban sprawl ratio has proliferated. Non-systematic development, increased migration, and sharp population growth have been predominant factors. These variables boosted the population and resulted in quickly built-up areas in the Peshawar district. The present research was to investigate spatial and temporal change in the urban sprawl from 2000 to 2018. Remotely sensed data and Maximum Likelihood Classification were used to investigate the urban sprawl. Remotely sensed data is fundamentally appropriate for providing information and characteristics for urban land cover on spatial and temporal scales. The results show that the total urban built-up areas were $54.39 \mathrm{~km}^{2}, 54.62 \mathrm{~km}^{2}, 64.64 \mathrm{~km}^{2}, 69.65 \mathrm{~km}^{2}$ and $77.39 \mathrm{~km}^{2}$ with annual growth rates of $0.084 \%, 3.06 \%, 1.43 \%$ and $3.3 \%$, respectively, in 2000, 2005, 2010, 2015 and 2018. The overall accuracy of the classified imagery was $80 \%$. Our finding of analysis shows that major changes were detected in the built-up area of Peshawar during this 18-year time period. According to the Peshawar Development Authority report, in 2017 the total urban built-up area was $84 \mathrm{~km}^{2}$ while our analysis shows that the total built area was $77 \mathrm{~km}^{2}$. The primary driving force for the development was education, health, and microeconomic centers, and the population shift to the Peshawar district from neighboring tribal regions because of military operations. It has been recommended that hyper spectral imagery would be useful for monitoring the urban expansion of larger cities.
\end{abstract}

Keywords: predominant factors, spatial and temporal, remote sensing, Maximum Likelihood Classification, hyper spectral imagery

\section{Introduction}

The term urban in Pakistan can be used when the population living in an area of any region is more than 5,000 persons, and they are subject to specific parameters including municipal services, socio-economic basis and access to basic facilities (Mehmood et al., 2016). The total urban population divided by the total population of the area is the formula to measure the urbanization of that region (Wen and Ren, 2017). Urban expansion is when the population expands outward from both the city and its suburb to peripheral areas to minimum-density as well as sometimes auto-dependent rural land growth (Gillham, 2002). In other words, urban expansion is the outer dispersion of urban areas to suburbs - meaning from a high bulk area to a low-density area. This urban sprawl happens due to the spread of the built-up areas onto the rural land (Foody, 2002; Jat et al., 2008).

Half of the world's population is living in metropolitan areas and cities. This ratio was about 33\% in 1960 and is predicted to reach up to $70 \%$ by 2050 (Mehmood et al., 
2016). Globally, big cities in all developed and developing countries, have lost their green areas or forest lands due to the very rapid conversion of agricultural land into the built-up areas (Dadras et al., 2015).

The main factors which cause urban expansion are a high standard of living, living and property expenditures, a developed transportation system, and basic health facilities such as hospitals etc. (Solé-Ollé et al., 2008). In developing countries, the rapid and uncontrolled population growth causes serious complications, such as a shortage of a nutritious food supply, unplanned settlements, ecological issues, and smog, all of which destroy of natural structure the area (Sudhira et al., 2004).

Approximately one-third of Pakistan's population lives in big cities. Pakistan's urbanization rate has grown from 4.9 to $6.5 \%$ per year in the last 40 years. Between 1951 and 1991, the overall population grew by 236 percent, while the urban population rose by 49.5 percent. Urbanization has resulted in two mega-cities Karachi (estimated to be 8-10 million), Lahore (approximately 5 million) and six cities with residents of one million (Qadeer, 1996).

Unplanned urbanization is also causing a huge problem in Peshawar. Due to the migration of Afghan refugees and IDP's from tribal areas, rapid urbanization took place in Peshawar district and urban areas grew and extended rapidly (Raziq et al., 2016). Urban settlements have expanded, and new urban areas have emerged in newly urbanized areas including Regi Model Town, Hayatabad Township, and a number of local projects. The transformation of this agricultural land into the built-up area damaged the agricultural industry and caused food scarcity at the local level (Rahim et al., 2015a). The Peshawar Development Authority might need to create a better development management system as well as a plan with only a sustainable development goal.

The urban area of Peshawar district is growing very quickly in terms of both population as well as spatial development. Because of this rapid spread, a large number of difficulties have emerged. In this circumstance, this study will concentrate on the rapid growth and unplanned development and illegal encroachment. Because of the growth and expansion in the city area, the peripheral zone, and green belt or farming land has very rapidly converted into a built-up area. The rapid sprawl of urban areas has led to a swift rise in land and property values. The main objectives of this research were to study the spatial and temporal trend of urban sprawl of Peshawar and to find out the causes of urban sprawl and the role of RS and GIS for future planning.

\section{Role of GIS and RS for sustainable urbanization}

The application of RS and GIS offers an effective scientific method to detect trends in land-use and determine their effects on the environment, which cannot be supported by fieldwork, and monitoring approaches by the authorities. Instead of wasting money on traditional methods, national and city, governments should incorporate RS and GIS technology to evaluate the extent, growth rate, and direction of land-use shifts. The emergence of satellite imagery has introduced valuable information sources for all those interested in urban planning. Sustainable land development projects must be built to determine the future direction and the trends of urban development in order to reduce the amount of farmland losses through urban planning. Governments can then implement policies and ideas to tackle the uncontrolled growth of city extension. RS and GIS applications are strong tools to support the decision-making process for controlling urban development. 
As a consequence, growing research attention has focused on mapping and measuring urban development using remote sensing (RS) and other approaches (Goetz, 2013). RS and GIS knowledge can be used proficiently in the investigation and cataloging of urban expansion and land use land cover changes as well as monitoring the growth of any city area (Shirazi and Kazmi, 2014). To monitor urban sprawl and to determine sustainable urbanization, precise and accurate data or information about urban sprawl patterns is needed (He et al., 2010). Remote sensing plays a vital role and technically efficient and widely used in the study of urban expansion. Over the last few years, remote sensing technologies have emerged, especially because of their low cost, broad spatial swath width, temporal resolution and powerful data acquisition capability. Thus, urban researchers and urban planners have been urged to use remote sensing data to track Spatio-temporal Land Use Land Cover (LULC) variation and city area growth (Seilheimer et al., 2007). For example, the application of Geo-informatics and remote sensing in studies of urban expansion in China have provided more effective and better results when gathering urban land use information (Zeng et al., 2008).

\section{Materials and methods}

\section{Study area}

Peshawar is one of the oldest and largest capital cities of Khyber Pakhtunkhwa. The Peshawar district is situated in the wide-ranging valley of Peshawar close to the eastern end of the historic Khyber Pass. Figure 1 represents the location map of the study area, Peshawar lies, $33^{\circ} 41^{\prime}$ to $34^{\circ} 12^{\prime}$ North latitude, and from $71^{\circ} 27^{\prime}$ to $71^{\circ} 47^{\prime}$ East longitude. The Peshawar district occupies a total land area of about $1,255 \mathrm{~km}^{2}$. Winter season usually occurs from the middle of November until mid-March. Summer runs from May until September. The local economy is supplemented by agricultural processing, manufacturing and industry. It is the regional epicenter for commercial and educational organizations and other utilities of the province. In the 1961 census report, $29 \%$ of the total urban population lived in Peshawar district. According to the 1998 census report, $33 \%$ of the population was found in urban areas of Peshawar as compared to the total population (PCO, 1998). After 1978, the relocation of Afghan migrants triggered the urban growth rate in the Peshawar city and in the 1998 census, the population reached 2.01 million without Afghan refugees (Turton and Marsden, 2002). Another factor seems to be that the sex ratio is 106.5 while the annual growth rate was 4\% between 1998-2017. As well, a number of dynamic business activities play a vital role in the expansion of the city (PCO, 2017).

\section{Data collection and processing}

Data collection was obtained from both primary and secondary sources. Remotely sensed multispectral satellite imagery of the $30 \times 30 \mathrm{~m}$ spatial resolution Landsat series was downloaded from the United States Geological Survey (USGS; http:/landsat.usgs.gov) for the corresponding path (151/) row (36 and 37) for the Peshawar district. The images were downloaded for the year 2000, 2005, 2010,2015 and 2018. The secondary data included detailed population information of the Peshawar district from 1998 and 2017 census reports. The methodological flow chart of the study is shown in Figure 2. 


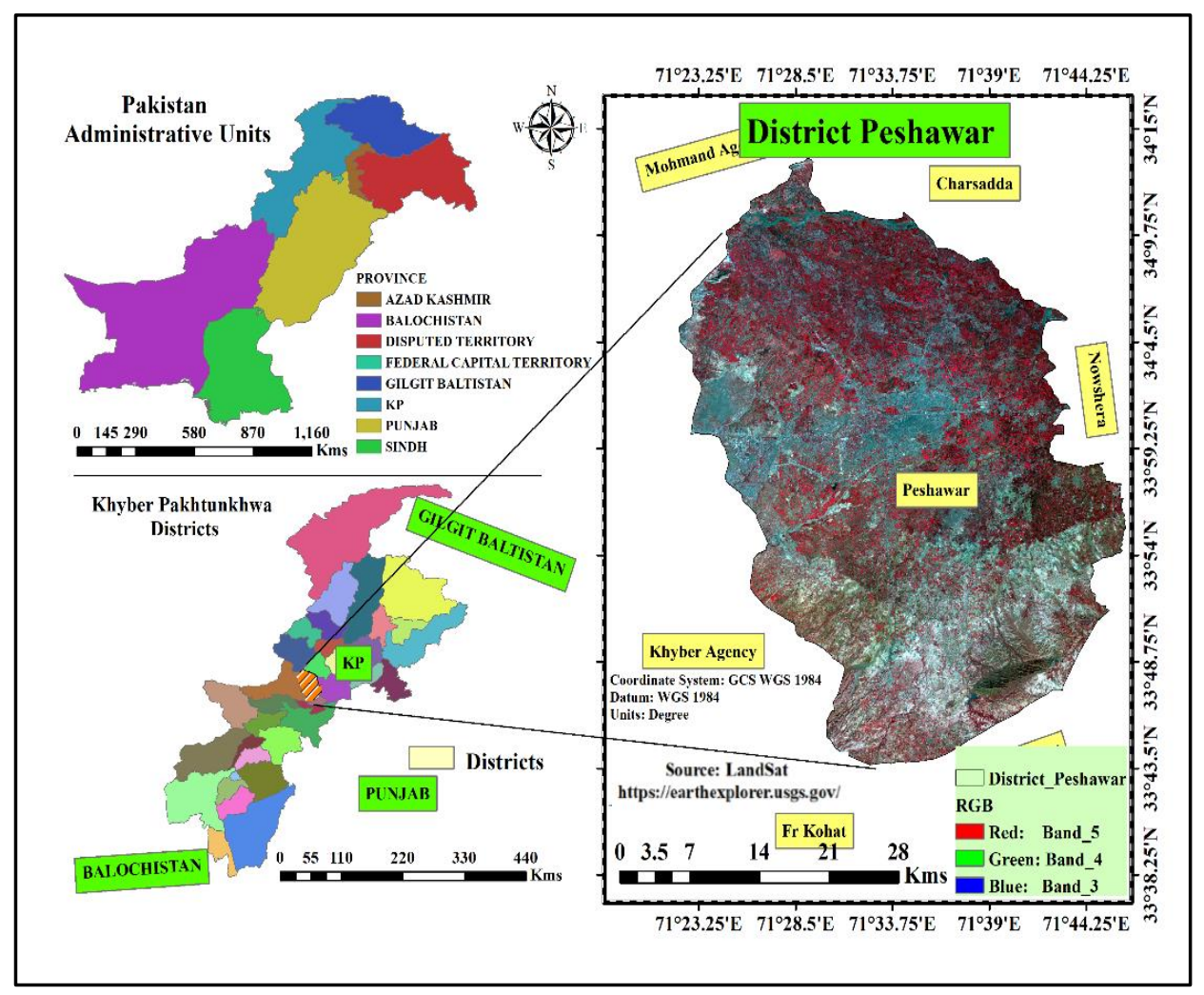

Figure 1. Locational Map of Peshawar District

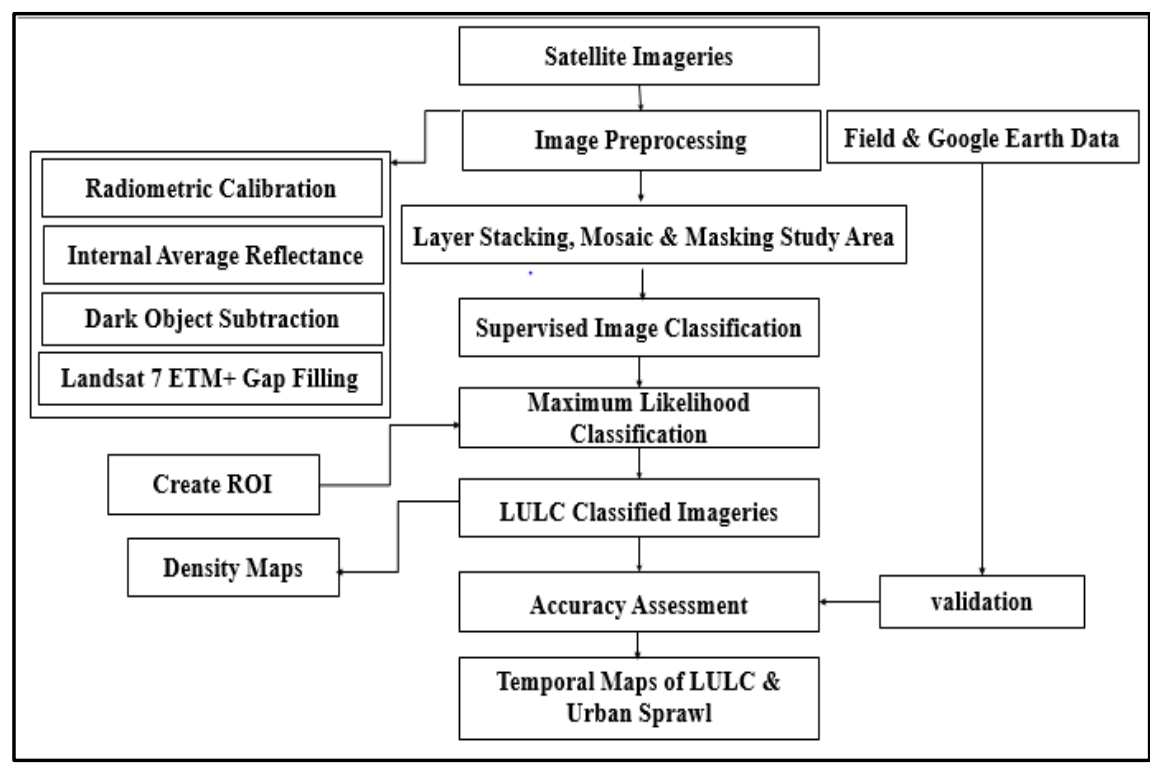

Figure 2. Flow Chart of Methodology

First of all, the atmospheric correction was implemented by using radiometric correction, gap filling, IAR reflectance, and DOS technique to bring entire images to common reference spectral characteristics by using ENVI classic 5.3 software (ENVI Version, 2009). Then, GIS was used to evaluate patterns and trends of land use in order 
to understand variations in urban development. The study area was masked from images with help from the territorial boundary of the Peshawar District. Satellite images have been analyzed in depth to evaluate possible land use classes. Five distinguishable land use classes were recognized and named: urban/built-up, vegetation, barren land, water bodies and areas under shadow regime (Table 1). Supervised classification using the MLC algorithm was performed for the categorization of multiple images (Ahmad and Quegan, 2012). The inherent problem in MLC techniques such as mixing between barren and builtup was addressed by the texture difference between the buildup class and the barren land class. Built-up area has rough texture while barren land has a smooth texture. Also, some random polygon samples of built area were taken on google earth to correlate with classified imageries of Landsat, which was classified through MLC. To improve the classification accuracy, a knowledge-based expert method was used for postclassification improvement of primary classified images (Foody, 2002; Zeng et al., 2008). The accuracy assessment of classified images was completed using field data. For the year 2018, 100 points were collected during the study area survey. More than 75 points for each year were randomly created on classified images of different years and validated with Google Earth for the years 2000, 2005, 2010 and 2015 complete detail are in Table 2. Finally, an error matrix was created. Maximum likelihood classification was applied to extract classified images and to map urban extensions over a period of 18 years.

Table 1. Different Land Use Land Cover description

\begin{tabular}{c|c}
\hline Class Name & Description \\
\hline Urban/built-up & built-up, commercial and service area, manufacturing, transportation etc. \\
\hline Agriculture farms & Cropland, agricultural farms, greenhouses other trees, etc. \\
\hline Bare land & Bare and exposed areas and soil \\
\hline Water bodies & Rivers, canals and water ponds \\
\hline shadow regime & areas under terrain shadow and low elevation as compared to surrounding area \\
\hline
\end{tabular}

\section{Results and discussion}

Results obtained from image analysis in Figure 3 show the amount of change over the 18-year period, where a significant portion of the agricultural and barren land was converted into the built-up area.

\section{Built-up area}

To estimate the probable land use classes, satellite images were thoroughly examined (Fonji and Taff, 2014; Mahboob and Iqbal, 2015), by using Arc Map software, we were able to estimate LULC temporal change for various years. This included approximately $195.71 \mathrm{~km}^{2}$ in 2000, $281 \mathrm{~km}^{2}$ in $2005,251 \mathrm{~km}^{2}$ in 2010 and then an increase to $483 \mathrm{~km}^{2}$ in 2015 while in 2018 it covered $511 \mathrm{~km}^{2}$ of the Peshawar District (see Figure 3 below). Figure 4 represents the Land use /Land cover classes of Peshawar district. Urban sprawl occurred in all directions from the main city, but most growth was directed south and west at the ring road and Chamkani Peshawar. Most growth was in town 3 and town 4. The built-up area increased along the main road network of Peshawar city. This increase was due to either people affected by the flood in 2010 or the approximately 2.5 million Afghani Refugees who migrated to Pakistan during the Soviet Union attack on Afghanistan from 1979 to 1989 (Turton and Marsden, 2002). From 2009 to 2012, there 
were around 3 million IDPs (Internally Displaced Persons) in Khyber Pakhtunkhwa (KP) mainly coming from the districts of Federally Administered Tribal Areas (FATA). In addition, one million people were relocated inside because of the flooding and about 5 million from Military operations against militants or Taliban in FATA. The number of IDP registered in KP was more than 3 million from 2009 to 2010 and it further increased from three lakhs up to seven lakhs in KP at the end of 2012. Nearly $43 \%$ of the registered IDPs lived in Peshawar (Roehrs, 2015). As indicated by the trend recorded in the 2017 census during the last period of 20 years, the rate of urban growth has accelerated in recent years. A socio-economic factor is one of the main causes of urban sprawl in Peshawar. Peshawar is Khyber Pakhtunkhwa's largest city, a major commercial and economic hub, and an integral role of the province's economy. Historically, Peshawar served as a gateway to Central Asia for traders and visitors (PCO, 2017).

Table 2. Overall percentage accuracy of the image classification of Peshawar derived from Landsat

\begin{tabular}{|c|c|c|c|c|c|}
\hline \multicolumn{6}{|c|}{ Landsat ETM+ 2000 (classification accuracy: $86.67 \%$ ) } \\
\hline & Built-Up & Vegetation & Barren land & Water Bodies & Shadow Regime \\
\hline Built-Up & 12 & 00 & 03 & 00 & 00 \\
\hline Vegetation & 00 & 21 & 04 & 00 & 00 \\
\hline Barren land & 01 & 01 & 27 & 01 & 00 \\
\hline Water Bodies & 00 & 00 & 00 & 03 & 00 \\
\hline Shadow Regime & 00 & 00 & 00 & 00 & 02 \\
\hline \multicolumn{6}{|c|}{ Landsat TM+ 2005 (classification accuracy: $81.33 \%$ ) } \\
\hline & Built-Up & Vegetation & Barren land & Water Bodies & Shadow Regime \\
\hline Built-Up & 14 & 01 & 03 & 00 & 00 \\
\hline \multirow[t]{2}{*}{ Vegetation } & 01 & 20 & 02 & 00 & 01 \\
\hline & 01 & 03 & 25 & 00 & 01 \\
\hline Water Bodies & 00 & 00 & 01 & 02 & 00 \\
\hline Shadow Regime & 00 & 00 & 00 & 00 & 00 \\
\hline \multicolumn{6}{|c|}{ Landsat TM+ 2010 (classification accuracy: $82.66 \%$ ) } \\
\hline & Built-Up & Vegetation & Barren land & Water Bodies & Shadow Regime \\
\hline Built-Up & 22 & 00 & 03 & 00 & 00 \\
\hline Vegetation & 02 & 16 & 02 & 00 & 00 \\
\hline Barren land & 01 & 02 & 17 & 00 & 01 \\
\hline Water Bodies & 00 & 01 & 00 & 05 & 01 \\
\hline Shadow Regime & 00 & 00 & 00 & 00 & 02 \\
\hline \multicolumn{6}{|c|}{ Landsat OLI+ 2015 (classification accuracy: $80 \%$ ) } \\
\hline & Built-Up & Vegetation & Barren land & Water Bodies & Shadow Regime \\
\hline Built-Up & 25 & 02 & 03 & 00 & 00 \\
\hline Vegetation & 02 & 05 & 02 & 00 & 00 \\
\hline Barren land & 02 & 01 & 29 & 00 & 01 \\
\hline Water Bodies & 00 & 01 & 00 & 01 & 00 \\
\hline Shadow Regime & 00 & 00 & 00 & 00 & 01 \\
\hline \multicolumn{6}{|c|}{ Landsat OLI+ 2015 (classification accuracy: 90\%) } \\
\hline & Built-Up & Vegetation & Barren land & Water Bodies & Shadow Regime \\
\hline Built-Up & 28 & 00 & 02 & 00 & 00 \\
\hline Vegetation & 03 & 37 & 02 & 00 & 00 \\
\hline Barren land & 00 & 03 & 20 & 00 & 00 \\
\hline Water Bodies & 00 & 00 & 00 & 04 & 00 \\
\hline Shadow Regime & 00 & 00 & 00 & 00 & 01 \\
\hline
\end{tabular}




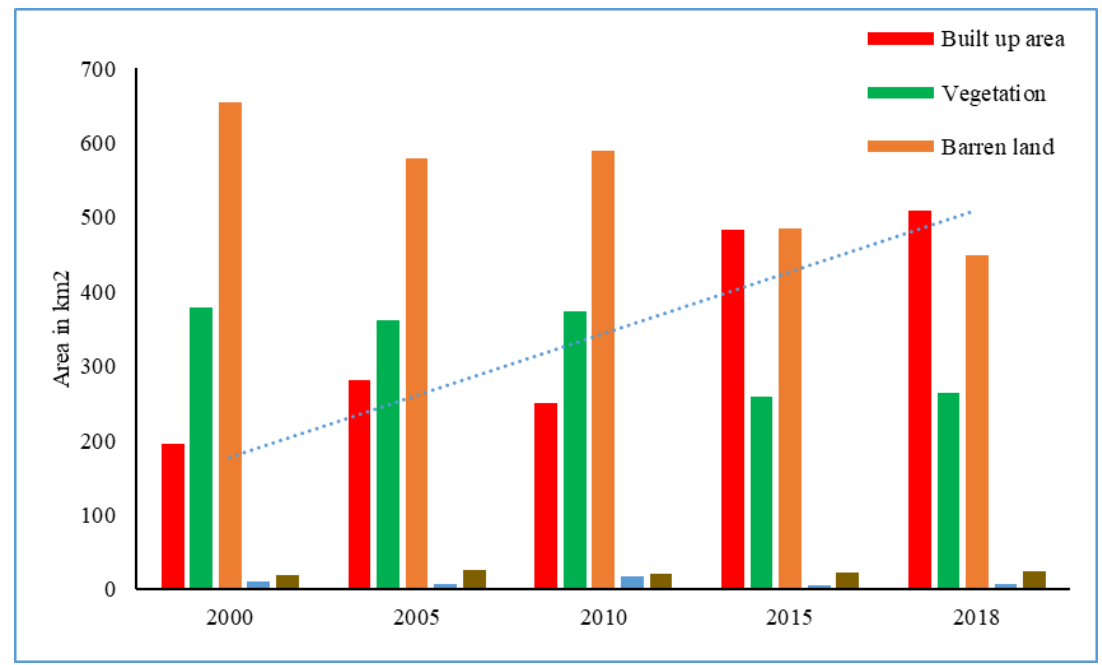

Figure 3. LULC Change in District Peshawar 2000-2018

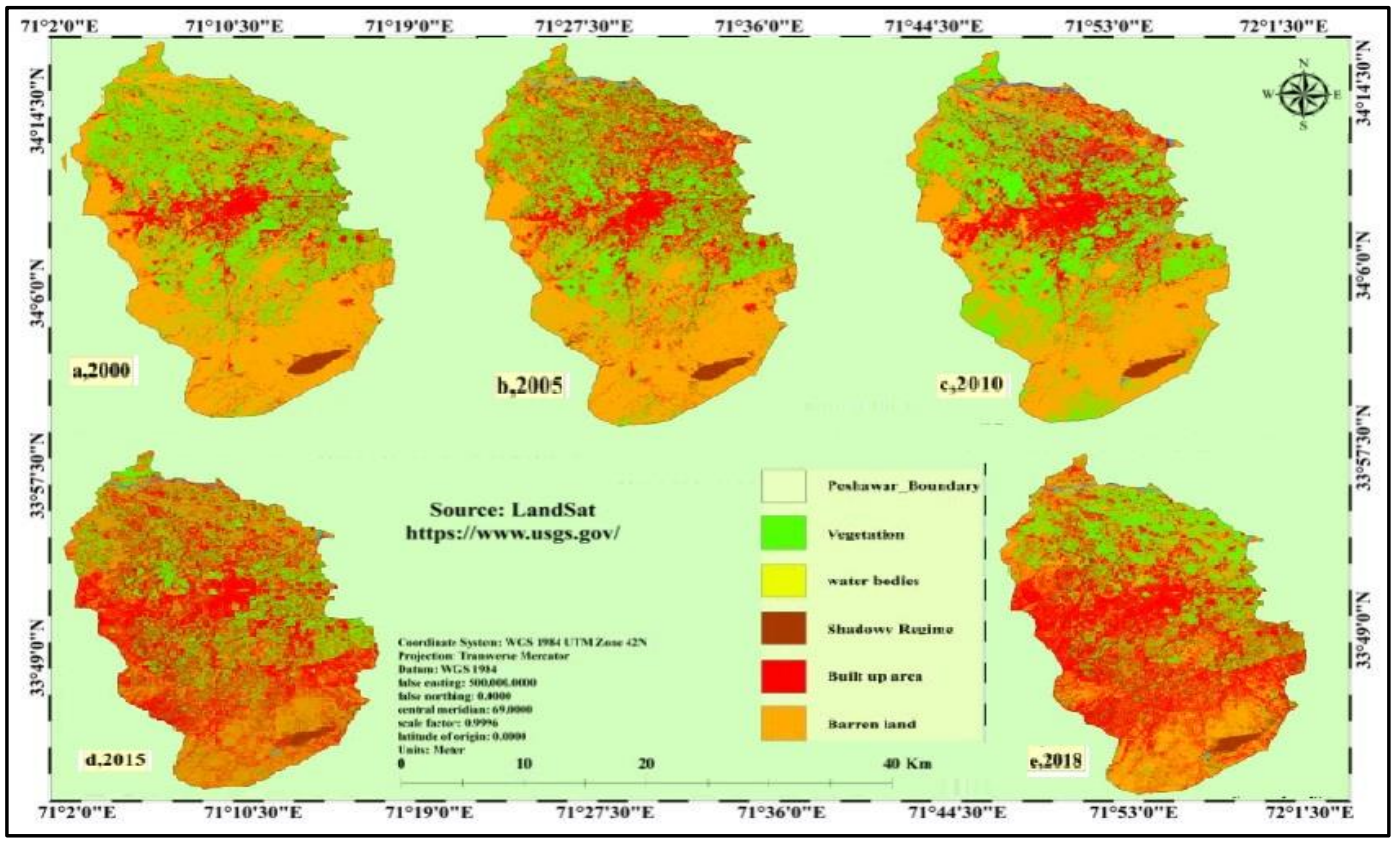

Figure 4. LULC Classification of Peshawar District (a) 2000, (b) 2005, (c) 2010, (d) 2015, (e) 2018

\section{Agricultural farms}

The study showed a huge decrease in the available agricultural land within the Peshawar district. The area of farmland was $379 \mathrm{~km}^{2}$ in $2008,361 \mathrm{~km}^{2}$ in $2005,373 \mathrm{~km}^{2}$ in 2010 and it further decreased down to $259 \mathrm{~km}^{2}$ in 2015 , while a minor increase of $04 \mathrm{~km}^{2}$ occurred in 2018. Ghaffar stated that the frequency of land loss due to urban development has been rising at an alarming rate, so it needs to be managed and monitored (Ahmed Khan Jatoo et al., 2016). 


\section{Barren land}

The results of this study show that the barren area declined from $655 \mathrm{~km}^{2}, 578 \mathrm{~km}^{2}$, $590 \mathrm{~km}^{2}, 485.47 \mathrm{~km}^{2}$ as well as $448.59 \mathrm{~km}^{2}$, respectively in 2000, 2005, 2010, 2015 and 2018. One significant decline in this class was $115 \mathrm{~km}^{2}$ while in total, barren land was reduced by $207 \mathrm{~km}^{2}$ in the 18 -year period from 2000 to 2018 .

Most of the land use for urban development was empty space in the town and leftover land between adjacent buildings. Eventually, the forested areas have also been transformed into the built-up zone (Ahmad and Goparaju, 2016).

It is clearly observed that in Peshawar, a decline in agricultural and barren land is due to the development of buildings, roads, houses and new residential communities in these areas.

\section{Water bodies and shadow regime}

Figure 3 also indicates that the total land area occupied by water class has a mixed value from 2000 to 2018 , but there was a $07 \mathrm{~km}^{2}$ increase in 2010 due to massive flood occurrences in Peshawar. However, after the flood, a rapid decline occurred. Similarly, the shadow regime area of approximately $24 \mathrm{~km}^{2}$ covered the southern part of the Peshawar district.

Figure 3 shows the results for LULC in Peshawar district from 2000 to 2018. Results show that the built-up area extends from $195.71 \mathrm{~km}^{2}$ to $281 \mathrm{~km}^{2}$ between 2000 and 2005 , while a $30 \mathrm{~km}^{2}$ decrease occurred in 2010 due to the devastating floods of 2010 . The built-up area increased by almost $232 \mathrm{~km}^{2}$ in the five years from 2010 to 2015. A considerable decrease occurred during 2000 - 2018 in vegetation and barren land by $115 \mathrm{~km}^{2}$ and $207 \mathrm{~km}^{2}$, respectively. While water bodies covered $0.15 \mathrm{~km}^{2}$ and the area under shadow cover was zero $\mathrm{km}^{2}$ in 2000. In 2005, the built-up area covered $54.62 \mathrm{~km}^{2}$, which increased by $10 \mathrm{~km}^{2}$ in 2010 . The built-up area further increased to $69.65 \mathrm{~km}^{2}$ in 2015. The built-up area rapidly increased in the next three years to $77.39 \mathrm{~km}^{2}$ (2015 to 2018).

The transformation of agricultural land into urban use may create a number of issues including political, cultural, environmental as well as social insecurity (Peerzado et al., 2018).

The built-up area has rapidly increased due to the growth of the indigenous population and the migration of people from rural areas to urban centers as shown in Figure 4. The trend line shows increase in built up area of Peshawar city which is the strong evidence of urban expansion in Peshawar city. This migration of Afghan refugees and people from the tribal regions due to the Taliban insurgency played a vital role in Peshawar city expansion and urban sprawl. In 2009 to 2012, there were around 3m IDPs in KP, mainly from other areas of KP Province and some districts of FATA (Roehrs, 2015). An additional $19 \mathrm{~m}$ people have been moved inside by the flooding and earthquakes as about $5 \mathrm{~m}$ by the armed fight against militants or Taliban in FATA and some districts of KP. The number of IDP register in Khyber Pakhtunkhwa over 3m from 2009 to 2010, currently, the number of registered IDP's was 774,594 in KP at the end of 2012. Nearly 43\% of registered IDPs lived in Peshawar (Roehrs, 2015).

Each of the Classified Map was matched with positional or field data to evaluate the accurateness of the classified image that is done with the supervised classification algorithm. The reference data were used for data organized by collecting through a random sample method with the help of field information and Google earth application 
to detect the particular location of the point and compare the classified accuracy with historical imageries of google Earth of Peshawar district. While for year of 2018, detail filed survey was conduct. Table 2 represents the overall accuracy of district Peshawar imagery Classification of the 2018 year was $90 \%$. User accuracy for built-up area class, vegetation, bare land, and water class as well as the Shadow regime were 93.33\%, $88.10 \%, 86.96 \%$, and $100 \%$, respectively. While Producer Accuracy for the above same classes were 90\%, 92\%, 83\%, 100\% and 100\% for the 2018 year of District Peshawar.

For the maximum likelihood classification for Peshawar district, in Figure 5 shows the urban areas in 2000, 2005, 2010, 2015 and 2018. In 2000, the total area covered by Peshawar city was $93 \mathrm{~km}^{2}$. In which, $54 \mathrm{~km}^{2}, 12 \mathrm{~km}^{2}$, and $26 \mathrm{~km}^{2}$ was covered by urban/built-up, Vegetation, and barren land, respectively. Linear line represents the builtup growth trend from the year of 2000 to 2018 respectively.

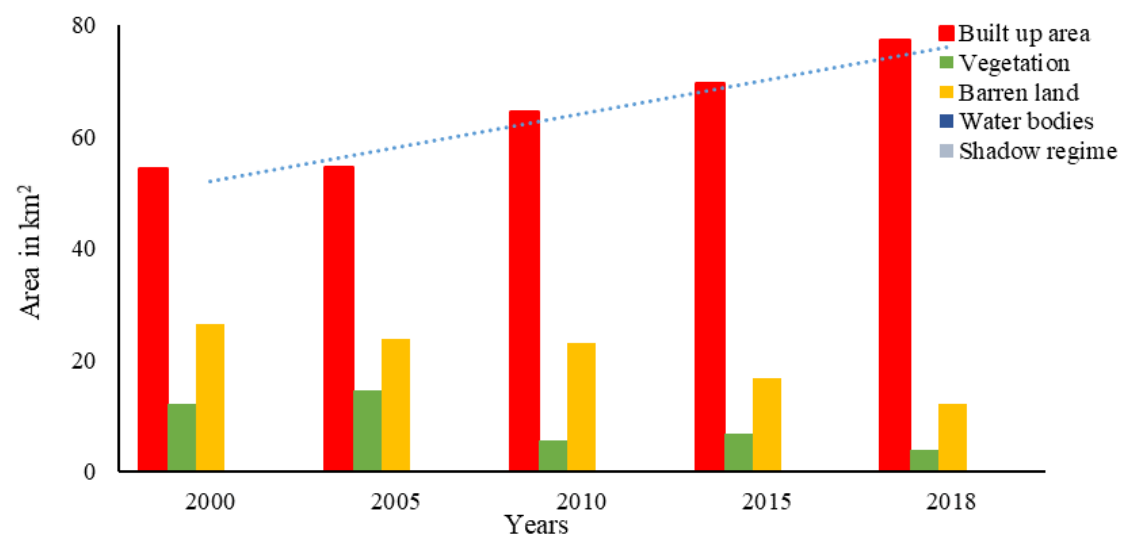

Figure 5. Temporal Change in land use and land cover in Peshawar city

As Raziq et al. (2016) stated, significant changes were noted in the region under development areas were grew steadily by 26.59 percent, but there was a significant decline in agricultural and barren land between 1999 and 2016.

In 1998, population census data was available, showing a 3.29 percent annual growth rate. For 2000, 2005, 2010, and 2015, the population was estimated using the annual growth rate and census data from 1998. Then, using 2017 census data and a 3.99 percent annual growth rate, estimate the population for 2018. A hypothetical linear trend between the five interval census years is represented by the diagonal line which shows increases in population in the Peshawar city (DCR, 2017) (Figure 6).

The overall patterns and variations of land-use change in Fez have been analyzed by categorizing the area of land that has been changed from forest and agricultural land to land used for residential areas (El Garouani et al., 2017). Figure 7 shows that most of the urban growth in the Peshawar district was unplanned. About $70 \%$ of the cultivated land area and 50\% of barren land were lost in the 18-year time period (2000-18). This loss was due to rapid and unplanned urban growth in Peshawar. Therefore, supposing the decline of farming land continued at the same rate, the remaining $4 \%$ of Peshawar urban cultivated land would probably reach zero in the next few years. Figure 7 demonstrates the loss of different land use land cover types in the 18 years from 2000 to 2018 because of urban sprawl. This will possibly destroy and reduce the limited farming lands, water assets, and biodiversity in the study area. The total planned area of district Peshawar is 
$30.99 \mathrm{~km}^{2}$ which includes, Hayatabad Sector, Peshawar Cantonment, and the University of Peshawar having an area of $13.35 \mathrm{~km}^{2}, 3.64 \mathrm{~km}^{2}$, and $4.00 \mathrm{~km}^{2}$, respectively.

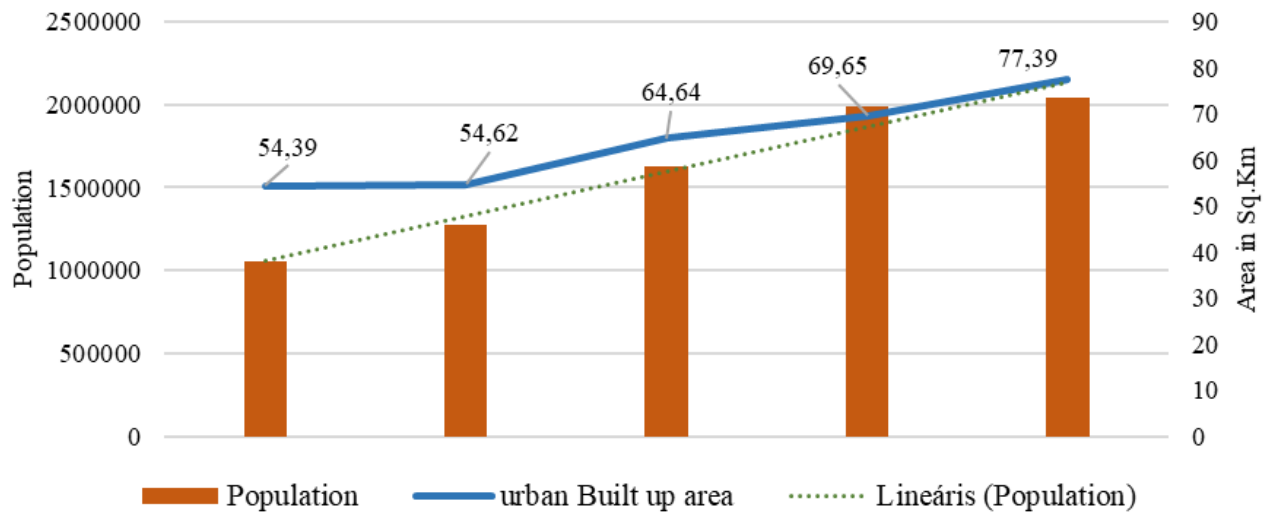

Figure 6. Temporal Change in land use and land cover in Peshawar city

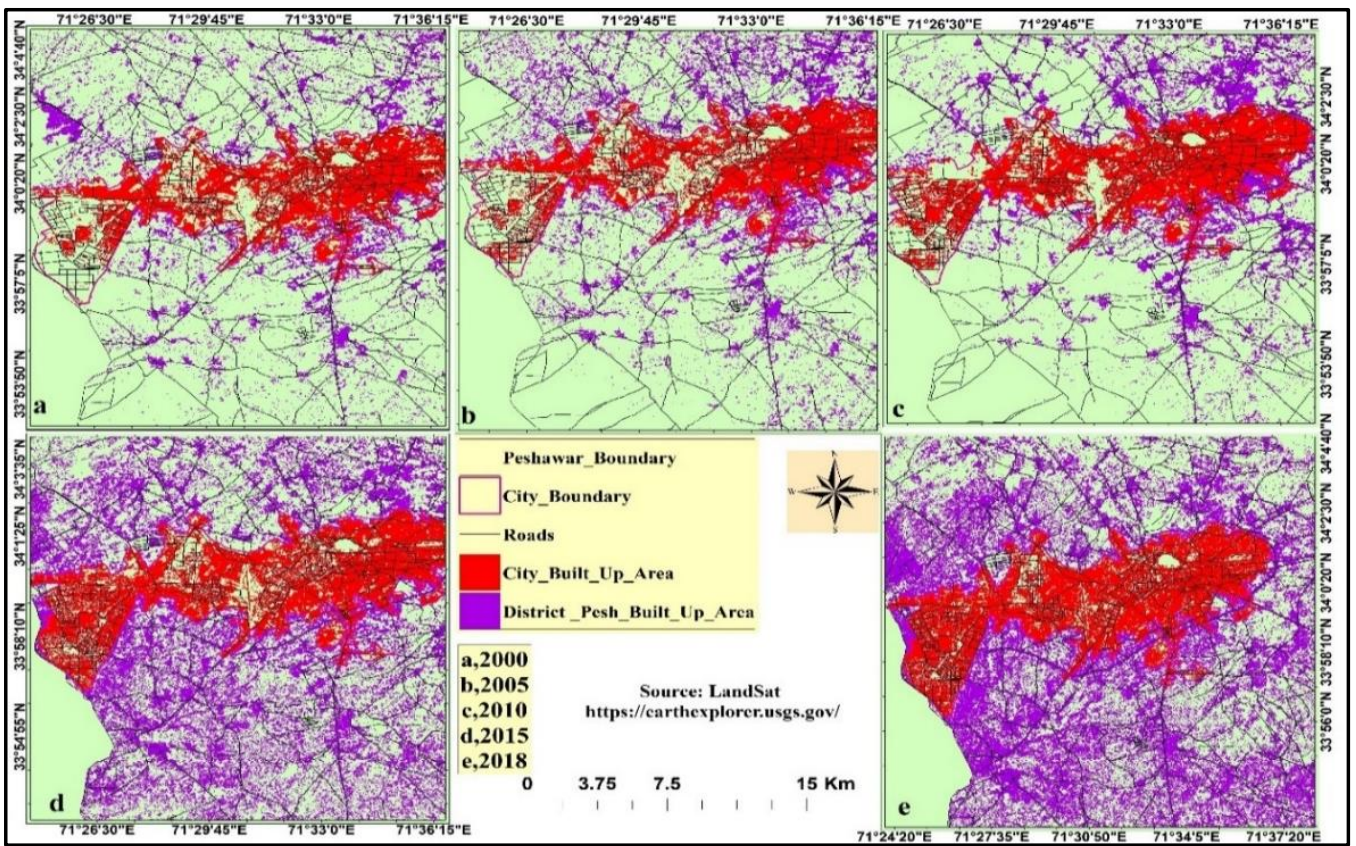

Figure 7. Built-up area expansion in the last 18 years in different direction in the Peshawar city

The statistic results from the calculation of temporal change in land use land cover shows that the built-up area has been growing at an annual growth rate of $0.084 \%, 3.06 \%$, $1.43 \%$ and $3.33 \%$ during the periods of 2000-2005, 2005-2010, 2010-2015 and 2015-2018, respectively in the Peshawar city with interval of five years but from 2015 to 2018 for three years (Table 3). Table 4 shows the detail change matrix i.e. the nature of change from one class to another class during 2000-2018.

For urban expansion in the city of Peshawar KP using multi-temporal Landsat data, classification findings indicate that over the last two periods, major increases occurred in the built-up area while there was a rapid decline in agricultural and barren land (Raziq et al., 2016). 
Table 3. Inter-censual growth rate of urban area of Peshawar

\begin{tabular}{c|c|c|c|c|c}
\hline S.No & Years & Change $\left.\mathbf{( K m}^{\mathbf{}}\right)$ & Change \% age & Time Span & Growth Rate \\
\hline 1 & $2000-2005$ & 0.23 & 0.42 & 5 year & 0.084 \\
2 & $2005-2010$ & 10.02 & 15.34 & 5 year & 3.06 \\
3 & $2010-2015$ & 5.01 & 7.19 & 5 year & 1.43 \\
4 & $2015-2018$ & 7.79 & 10 & 3 year & 3.33 \\
\hline
\end{tabular}

Table 4. Change matrix from one class to another class during 2000-2018

\begin{tabular}{|c|c|c|c|c|c|c|c|c|c|c|}
\hline \multirow{2}{*}{ LULC Classes } & \multicolumn{2}{|c|}{2000} & \multicolumn{2}{|c|}{2005} & \multicolumn{2}{|c|}{2010} & \multicolumn{2}{|c|}{2015} & \multicolumn{2}{|c|}{2018} \\
\hline & $\mathbf{U L}$ & C or DL & $\mathbf{U L}$ & C or DL & $\mathbf{U L}$ & C or DL & UL & C or DL & $\mathbf{U L}$ & C or DL \\
\hline Built up & 54.39 & 195.71 & 54.62 & 281 & 64.64 & 251.01 & 69.65 & 483.87 & 77.39 & 509.66 \\
\hline Vegetation & 379.18 & 12.02 & 361 & 14.63 & 373.03 & 5.59 & 247.3 & 6.73 & 243.85 & 3.87 \\
\hline Barren Land & 651.06 & 26.49 & 578.28 & 23.75 & 590.01 & 23.11 & 485.47 & 16.71 & 448.59 & 12.11 \\
\hline water Bodies & 10.8 & 0.15 & 8 & 0 & 17.12 & 0.11 & 5.35 & 0 & 6.46 & 0 \\
\hline Shadow Regime & 17.71 & 0.07 & 25.87 & 0.01 & 21.3 & 0 & 23.25 & 0 & 39.23 & 0 \\
\hline
\end{tabular}

LULC: Land Use \& Land Cover, UL: At Urban Level, C or DL: At City or District Level

\section{Built-up area densities of Peshawar city}

Map density values are calculated by dividing the number of built-in pixels to the actual number of pixels in the kernel. It converts the land cover class to a density category when applied to a classified satellite image (see Figure 8 ). Based on the density scale, it can be additionally classified into low $(<20)$, low medium (21-40), medium (41-60), medium high (61-80) and high-density (>81) \% built up area (Fig. 8). On this basis, the relative percentage of each class was calculated. The calculation of the built-up density resulted in the distribution of high, medium-high, medium and low-medium and lowdensity groups in Peshawar city. The high density of built-up areas may denote the compact and more clustered form of the built-up pattern, followed by the medium high class, whereas medium density would refer to the comparatively less dense built-up areas. Low medium class and low density of broadly and sparsely spaced built-up zones also exist. In Figure 8, the red and blue colors represent a high and medium high-density category, which expanded rapidly from 2000 to 2018, especially in the south-west direction. This was likely due to the development of road and transportation networks and the small industrial area in the city.

\section{Major causing factors of urban sprawl in Peshawar}

In comparison to demographic figures of the district, the 1998 census report total population was 2,019,000 while in the 2017 census total population of Peshawar was 4,269,079 (DCR, 1998, 2017). Urban development also refers to many relevant factors such as construction, transportation, sanitation system, deforestation, water supply as well as industrial processes. Such factors are directly or indirectly related to the urban extension, there are 2018 public and private schools, 616 public and private universities respectively. There 18 major public as well as a private hospital and 52 dispensaries (Saleem Adnan, 2017). 


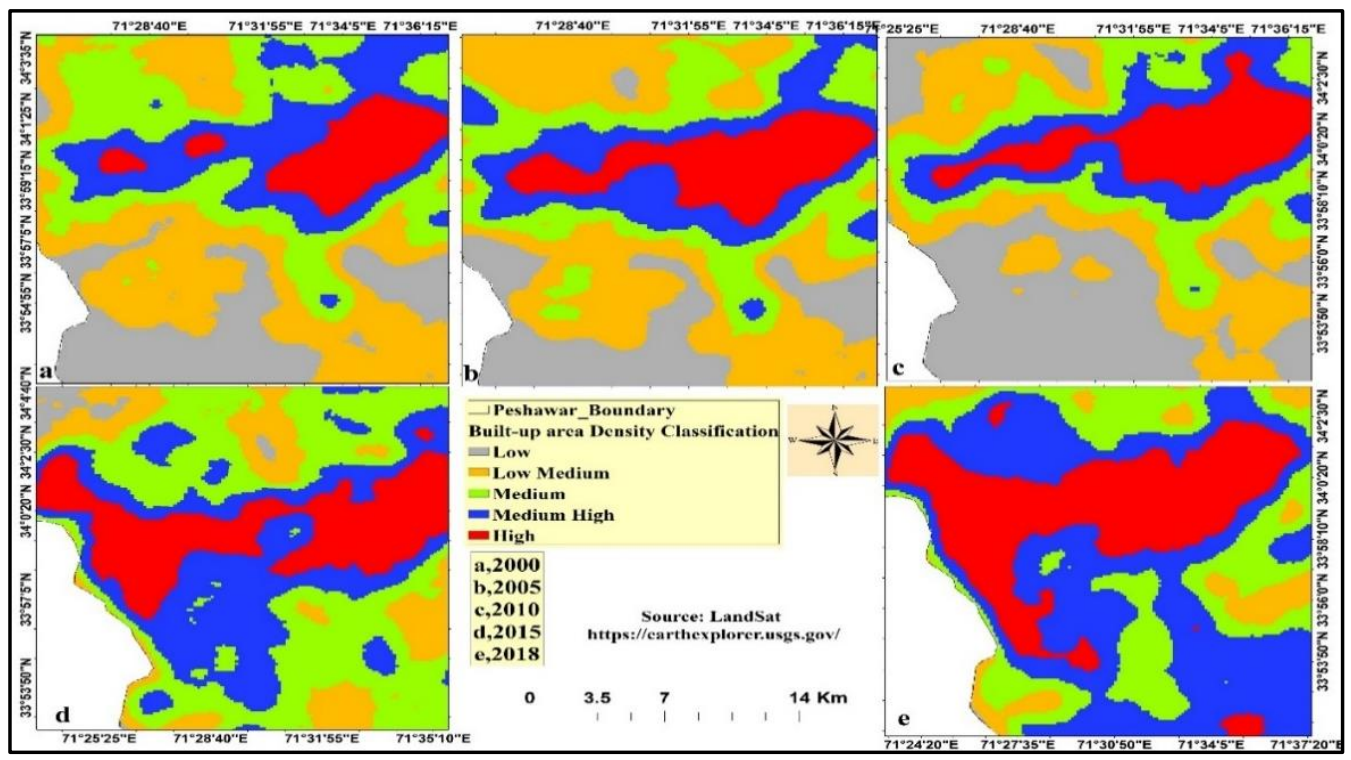

Figure 8. Classification of built-up area densities of Peshawar city

Three million afghan refuge migrated to Peshawar in 1979 due to country war and terror situations (Turton, 2000), where 31,284 registered families were still living in Peshawar. From 2009 to 2012, approximately 3 million IDPs migrated from different areas of the KPK Province to Peshawar and some districts of FATA. An additional 19 million people have been moved inside by the flooding and earthquakes. About 5 million were migrated due to armed fight against militants or Taliban in FATA and some districts of KPK (Roehrs, 2015).

\section{Conclusions}

Various local administrations, particularly those at the urban level, do not have a team of professionals that can observe land expansion that is quickly taking place all over Peshawar city. By using the combination of RS data and GIS techniques to analyze the nature, growth rate and location of land-use variations, local governments can recognize cities and towns that are overtaking a lot of valuable agricultural and cultivated land. They can then formulate strategies and guidelines to deal with such uncontrolled development. The integration of RS and GIS is a powerful tool and decision-support system for urban development. Remote sensing and GIS provide an effective and systematic way to monitor land-use variations and estimate their influences on the environment, which cannot be provided by fieldwork and government reporting methods. It has been found that the increase in built-up area over several 5-year intervals was $0.42 \%, 15.34 \%, 7.19 \%$ and $10 \%$ from 2000 to 2005,2005 to $2010,2010-2015$ and 2015 to 2018 , respectively. Urban sprawl is mainly seen in the western and southern parts of Peshawar city along the roadside. The westward increase was mainly due to Afghan refugees, IDP's from tribal territories and hazardous floods in the northern part of Peshawar. The study found that many buildings and built-up sites were developed on valuable good quality cultivated and barren land. As food supply is a chief factor of sustainable expansion, it is essential to ensure that unwarranted urban growth can be prevented as much as possible on valuable agricultural land. The results acquired from this Landsat imagery show that the land cover 
type arrangement of an urban area and highly urbanized areas can be effectively identified using a carefully built methodology for image analysis. This technique should be applied at a global scale, given its dependence on moderate spatial resolution image data and the combination of standard image processing procedures. Changes in the composition can also be identified over time as a basis for analyzing the complexity of urban development, but the precision of this analyzes depends heavily on the quality of the original images of the forms of land cover. Furthermore, other causal factors, such as socio-economic conditions, government funding for public projects, the extent of industrialization, barriers and distances from major locations, can also be considered in future research for urban sprawl modeling. To mitigate the amount of agricultural loss from urbanization, a sustainable land development strategy that guides the future direction and trend of urban growth needs to be implemented.

The study's results have conceptual and methodological significance; future research will focus on the entire city of Peshawar, as well as the environmental and socioecological aspects of urban sprawl. This future research study will help in urban planning and the development of a sustainable metropolis in Khyber Pakhtunkhwa, Pakistan. This will help to establish a sustainable strategy to protect useful agricultural land from urbanization and to organize the time and geographical coordinates of urban development.

\section{REFERENCES}

[1] Ahmad, A., Quegan, S. (2012): Analysis of Maximum Likelihood Classification Technique on Landsat 5 TM Satellite Data of Tropical Land Covers. - 2012 IEEE Conference, pp. 280-285.

[2] Ahmad, F., Goparaju, L. (2016): Analysis of Urban Sprawl Dynamics Using Geospatial Technology in Ranchi City, Jharkhand, India. - Journal of Environmental Geography 9(12): 7-13. https://doi.org/10.1515/jengeo-2016-0002.

[3] Ahmed Khan Jatoo, W., Chen, J. F., Saengkrod, W., Mastoi, A. G. (2016): Urbanization in Pakistan: Challenges and Way Forward (Options) For Sustainable Urban Development. Proceedings of the $4^{\text {th }}$ International Conference on Energy, Environment and Sustainable Development (EESD 2016). http://eesd.muet.edu.pk/sites/default/files/imagecache/EESD_2016_paper_243.pdf.

[4] Dadras, M., Shafri, H. Z. M., Ahmad, N. (2015): Spatio-temporal analysis of urban growth from remote sensing data in Bandar Abbas city, Iran. - The Egyptian Journal of Remote Sensing and Space Sciences 18(1): 35-52. https://doi.org/10.1016/j.ejrs.2015.03.005.

[5] El Garouani, A., Mulla, D. J., El Garouani, S., Knight, J. (2017): Analysis of urban growth and sprawl from remote sensing data: Case of Fez, Morocco. - International Journal of Sustainable Built Environment 6(1): 160-169. https://doi.org/10.1016/j.ijsbe.2017.02.003.

[6] ENVI (2009): ENVI User's Guide. - Pennsylvania State University.

[7] Fonji, S. F., Taff, G. N. (2014): Using satellite data to monitor land-use land-cover change in North-eastern Latvia. - SpringerPlus 3(1): 1-15. https://doi.org/10.1186/2193-1801-361.

[8] Foody, G. M. (2002): Status of land cover classification accuracy assessment. - Remote Sensing of Environment 80(1): 185-201.

[9] Gillham, O. (2002): The limitless city: a primer on the urban sprawl debate. - Island Press.

[10] Goetz, A. (2013): Suburban sprawl or urban centres: Tensions and contradictions of smart growth approaches in Denver, Colorado. - Urban Studies 50(11): 2178-2195. 
[11] He, C., Shi, P., Xie, D., Zhao, Y. (2010): Improving the normalized difference built- up index to map urban built-up areas using a semiautomatic segmentation approach. - Remote Sensing Letters 1(4). https://doi.org/10.1080/01431161.2010.481681

[12] Jat, M. K., Garg, P. K., Khare, D. (2008): Monitoring and modelling of urban sprawl using remote sensing and GIS techniques. - International Journal of Applied Earth Observation and Geoinformation 10(1): 26-43. https://doi.org/10.1016/j.jag.2007.04.002.

[13] Majd, M. S., Mans, L. (2012): Maximum Likelihood Classification of Single Highresolution Polarimetric SAR Images in Urban Areas. - https://doi.org/10.1127/1432$8364 / 20$.

[14] Mehmood, R., Mehmood, S. A., Butt, M. A., Younas, I., Adrees, M. (2016): Spatiotemporal Analysis of Urban Sprawl and Its Contributions to Climate and Environment of Peshawar Using Remote Sensing and GIS Techniques. - Journal of Geographic Information System 08(02): 137-148.

https://doi.org/10.4236/jgis.2016.82013.

[15] PCO. (1998): $6^{\text {th }}$ Population and Housing census survey. - District Census Report of Peshawar: Pakistan Census Organization.

[16] PCO. (2017): $7^{\text {th }}$ Population and Housing census survey. - District Census Report of Peshawar: Pakistan Census Organization.

[17] Peerzado, M. B., Magsi, H., Sheikh, M. J. (2018): Land use conflicts and urban sprawl: Conversion of agriculture lands into urbanization in Hyderabad, Pakistan. - Journal of the Saudi Society of Agricultural Sciences. https://doi.org/10.1016/j.jssas.2018.02.002.

[18] Qadeer, M. A. (1996): An assessment of Pakistan's urban policies, 1947-1997. - Pakistan Development Review 35(4 PART 2): 443-465. https://doi.org/10.30541/v35i4iipp.443465.

[19] Rahim, A., Khan, K., Jamal, R., Tariq, N., Akif, A. (2015): The Spatial and Temporal Variation in the Ground Water Potential Due to Urbanization in the Peshawar Regime of Pakistan. - Science International 27(3): 2225-2233.

[20] Raziq, A., Xu, A., Li, Y. (2016): Monitoring of Land Use/Land Cover Changes and Urban Sprawl in Peshawar City in Khyber Pakhtunkhwa: An Application of Geo- Information Techniques Using of Multi-Temporal Satellite Data. - Journal of Remote Sensing \& GIS 5: 4. https://doi.org/10.4172/2469-4134.1000174.

[21] Roehrs, A. C. (2015): The Refugee Dilemma: Afghans in Pakistan between expulsion and failing aid schemes. - Afghanistan Analysts Network, September 2018, 1-11.

[22] Salem Adnan, Q. F. (2017): Urban Policy and Planning Unit - Provincial Land Use Plan (PLUP). - Planning and Development Department Government of Khyber Pakhtunkhwa Final Land Use Plan of District Peshawar (Issue 306). https://urbanpolicyunit.gkp.pk/provincial-land-use-plan-phase-2/.

[23] Seilheimer, T. S., Wei, A., Chow-Fraser, P., Eyles, N. (2007): Impact of urbanization on the water quality, fish habitat, and fish community of a Lake Ontario marsh, Frenchman's Bay. - Urban Ecosystems 10(3): 299-319.

[24] Shirazi, S., Kazmi, S. (2014): Analysis of Population Growth and Urban Development in Lahore-Pakistan using Geospatial Techniques: Suggesting some future Options. - South Asian Studies 29: 269-280. http://pu.edu.pk/images/journal/csas/PDF/20 Safdar Shirazi_29_1.pdf.

[25] Solé-Ollé, A., Hortas-Rico, M. (2008): Does Urban Sprawl Increase the Costs of Providing Localpublic Services? Evidence from Spanish Municipalities. - Documents De Treball De L'Ieb 6: 1-33.

[26] Sudhira, H. S., Ramachandra, T. V., Jagadish, K. S. (2004): Urban sprawl: Metrics, dynamics and modelling using GIS. - International Journal of Applied Earth Observation and Geoinformation 5(1): 29-39. https://doi.org/10.1016/j.jag.2003.08.002.

[27] Turton, D., Marsden, P. (2002): Taking Refugees for a Ride? The politics of refugee return to Afghanistan. - The Afghanistan Research and Evaluation Unit (AREU). 
[28] Wen, F., Ren, L. (2017): The measurement of urbanization level based on entity space: A case study of JingJinJi region, China. - MATEC Web of Conferences, 100. https://doi.org/10.1051/matecconf/201710005046.

[29] Zeng, F., Cui, K., Xie, Z., Wu, L., Liu, M., Sun, G., Lin, Y., Luo, D., Zeng, Z. (2008): Phthalate esters (PAEs): Emerging organic contaminants in agricultural soils in peri-urban areas around Guangzhou, China. - Environmental Pollution 156(2): 425-434.

https://doi.org/10.1016/j.envpol.2008.01.045. 